\title{
Human papillomavirus infection in Shenyang City, People's Republic of China: a population-based study
}

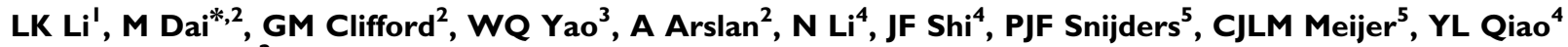 \\ and $\mathbf{S}$ Franceschi ${ }^{2}$ \\ 'Department of Gynecological Oncology, Liaoning Provincial Tumor Hospital, 44 Xiaoheyan Road, Shenyang I l 0042, Liaoning Province, China; \\ ${ }^{2}$ International Agency for Research on Cancer, 150 cours Albert Thomas, 69372 Lyon cedex 08, France; ${ }^{3}$ Department of Cancer Epidemiology, Liaoning \\ Provincial Tumor Hospital, 44 Xiaoheyan Road, Shenyang I l 0042, Liaoning Province, China; ${ }^{4}$ Cancer Institute/Hospital, Chinese Academy of Medical \\ Sciences, 17, South Pan Jia Yuan LN, PO box 2258, Beijing 100021. China; ${ }^{5}$ Vrije University Medical Center, Postbus 7057, 1007 MB Amsterdam, \\ The Netherlands
}

To investigate the prevalence of, and risk factors for, cervical infection with human papillomavirus (HPV) in Shenyang City, People's Republic of China, we interviewed and obtained cervical cell samples from 685 women aged I5-59 years enumerated from local population lists. Human papillomavirus DNA was detected in cervical cell samples using a GP5 + 16 + -based PCR assay for 44 HPV types. Human papillomavirus prevalence was $16.8 \%$ overall and $13.6 \%$ among women without cervical abnormalities (I6.6\% and 12.4\%, respectively, age-standardised to the world standard population), with no significant trends in HPV prevalence by age group. Of the 32 types identified, high-risk HPV types predominated in all age groups, HPV 6 being the most common (3.4\% of all women), followed by HPV52 (2.5\%) and 58 (1.9\%). Multiple-type infections accounted for $31.3 \%$ of all infected women. Not being married, reporting multiple sexual partners and husband's extramarital sexual relationships were all significantly associated with being HPV-positive. The disclosure of a relatively high HPV prevalence in Shenyang, in comparison with other worldwide populations, raises important questions concerning the prevention of cervical cancer in China, especially given the promising efficacy of prophylactic HPV vaccines.

British Journal of Cancer (2006) 95, I593- 1597. doi: I0.1038/sj.bjc.6603450 www.bjcancer.com

Published online 31 October 2006

(c) 2006 Cancer Research UK

Keywords: human papillomavirus; cervical neoplasia; China; epidemiology

Human papillomavirus (HPV) has been established as a necessary cause of cervical cancer, and HPV prevalence in any given population correlates well with cervical cancer risk (Anh et al, 2003; Sukvirach et al, 2003). The People's Republic of China has historically been considered at relatively low risk for cervical cancer (Parkin et al, 2002), but nationwide mortality surveys show a variable pattern of risk across the country (Yang et al, 2003a), which is on the increase among younger women, particularly in urban settings (Yang et al, 2003b). This phenomenon is probably related to behavioural changes accompanying rapid industrialisation and urbanisation, and concurrent increases of incidence of sexually transmitted diseases (Chen et al, 2000). In particular, population mobility and changes in sexual behaviour are expected to have increased the burden of HPV infection. Indeed, a recent study has shown high HPV prevalence in a rural Chinese community known to be at high cervical cancer risk (Dai et al, 2006).

In Shenyang City in Liaoning Province, the largest city in northeast China, the population had grown to 7.2 million in 2000 , with an annual increase of $7.4 \%$ (The fifth national census in 2000,

*Correspondence: Dr M Dai; E-mail: dai@iarc.fr

Received 14 August 2006; revised 27 September 2006; accepted 2 October 2006; published online 3I October 2006
Liaoning Provincial Statistics Bureau Online, http://www.stats. gov.cn). No recent data on cervical cancer exist from the city. The present study aimed to collect data on the age- and type-specific distribution of HPV infection in the urban environment of Shenyang, China, in the framework of a multicentre study coordinated by the International Agency for Research on Cancer (IARC) (Clifford et al, 2005).

\section{MATERIALS AND METHODS}

\section{Study subjects}

A list of 1479 women aged 15-59 years was obtained in June and July 2005 from the population list of a residential neighbourhood in Dadong District, Shenyang City. The study purpose was to enrol approximately 100 women in each 5-year age group between 15-19 and 55-59 years. Women were contacted at their home by local administrators and invited for an interview, blood sample collection and gynaecological examination in the study clinic situated in the same district. All mentally and physically competent women aged 15-59 years were eligible for the study, regardless of their marital status. However, gynaecological examination was not carried out on hysterectomised or pregnant women, and was known to be unacceptable to many unmarried women. 
Of the 1479 enumerated women, 47 were not found at the address given on the population list, and 41 were not invited as the required sample size for their age group had been reached. Of the 1391 invited women, $391(28.1 \%)$ did not accept the invitation to participate in the study, mainly citing that they did not have enough time or did not think they needed a gynaecological examination. The proportion of nonparticipation was largest $(31.2 \%)$ among women under 25 years of age. Of an additional 293 interviewed participants who came to the study clinic but refused to undergo gynaecological examination and, hence, a cervical cell specimen collection, 273 (93.2\%) were unmarried.

All participants signed an informed consent form according to the recommendations of the IARC and the Cancer Institute of the Chinese Academy of Medical Sciences ethical review committees, which approved the study.

\section{Study procedures}

Study procedures were identical to those reported in a preceding IARC HPV prevalence survey in China (Dai et al, 2006). In summary, a standardised risk factor interview was administered to all participants. Then participating women underwent a pelvic examination, and had a sample of exfoliated cervical cells collected for liquid-based cytology and HPV testing. On account of the high proportion of histological confirmation, cervical abnormalities were defined in the present study as presence of histologically confirmed cervical intraepithelial neoplasia (CIN) grade 1 or worse.

Human papillomavirus detection was performed in the Department of Pathology at the Vrije University Medical Center, Amsterdam, the Netherlands, using a GP5 + /6+ PCR-based enzyme immunoassay (Jacobs et al, 2000). Genotyping of 44 HPV types (HPV 6, 11, 16, 18, 26, 30, 31, 32, 33, 34, 35, 39, 40, 42, $43,44,45,51,52,53,54,55,56,57,58,59,61,64,66,67,68,69,70$, 71 (equivalent to CP8061), 72, 73, 81 (equivalent to CP8304), 82 (IS39 and MM4 subtypes), 83 (equivalent to MM7), 84 (equivalent to MM8), cand85, 86, cand89 (equivalent to CP6108) and JC9710) was performed by reverse line blot hybridisation of PCR products (van den Brule et al, 2002), and HPV types were classified, for some analyses, into high- and low-risk types (Dai et al, 2006).

\section{Statistical analysis}

Human papillomavirus prevalence was standardised by age by applying age-specific prevalence estimates for the age groups 15$24,25-34,35-44,45-54$ and 55-59 years to the world standard population reported by Doll et al (1966).

Odds ratios (ORs) for HPV positivity and corresponding 95\% confidence intervals (CIs) were calculated by means of unconditional logistic regression equations, adjusted for age $(15-24,25-$ $34,35-44,45-54,55-59$ years). The statistical significance of trends for ORs was assessed by considering the categorical variables as a continuous variable in the logistic model.

\section{RESULTS}

Of the 707 women who provided cervical cell samples, eight had inadequate cytology results and 14 had $\beta$-globin-negative samples, leaving 685 women with valid cytology and HPV results, which were included in the analyses that follow. Among them, $29(4.2 \%)$ had histologically confirmed cervical abnormalities, including 19 CIN1, eight CIN2 and two CIN3.

The prevalence of any HPV type was $16.8 \%(89.7 \%$ and $13.6 \%$ among women with and without cervical abnormalities, respectively, Table 1). The corresponding prevalences, age-standardised to the world population, were $16.6 \%$ overall, and $12.4 \%$ among those without cervical abnormalities. In total, 79 women had single-type and 36 had multiple-type infections. In all, 32 individual HPV types were identified.

High-risk HPV types were substantially more frequent $(11.7 \%$ of all women) than low-risk types (6.4\%). The most common types in either single- or multiple-type infections were HPV16 (3.4\%), $52(2.5 \%)$ and $58(1.9 \%)$, but HPV type distribution varied by the presence of cervical abnormalities. High-risk HPV types were found in $79.3 \%$ of women with cervical abnormalities. The two women identified with CIN3 were HPV16-positive.

Figure 1 shows the age-specific prevalence of HPV, classified hierarchically into (1) HPV 16 or 18, (2) other high-risk types and (3) low-risk types only. Human papillomavirus prevalence was not statistically different across age groups but the lowest prevalence estimate was seen in the 55-59-year age group. High-risk HPV types predominated across all age groups, but HPV 16 and 18 tended to diminish among older women.

Table 2 shows the relationship between HPV positivity and marital status, indicators of sexual behaviour, and use of contraceptive methods, after adjustment for age. Human papillomavirus prevalence was similar among women who were divorced/ separated $(27.8 \%)$ or widowed $(25.0 \%)$, who showed significantly higher prevalence than married women $(\mathrm{OR}=2.1,95 \% \mathrm{CI}$ : $1.1-3.9$ ). Among only 12 single women who underwent gynaecological examination, three were HPV-positive. There was no significant association between age at first sexual intercourse and HPV positivity. Reporting of multiple lifetime sexual partners $\left(\mathrm{OR}_{\geqslant 2}\right.$ vs 1 partner $\left.=1.8,95 \% \mathrm{CI}: 1.1-3.0\right)$ and husband's extramarital sexual relationships $(\mathrm{OR}=2.5,95 \% \mathrm{CI}$ : $1.6-3.7)$ were significantly associated with HPV positivity. Intrauterine device was the most commonly used contraceptive method $(78.4 \%$ of study women), followed by condoms (58.1\%), whereas only $11.5 \%$ of study women reported any oral contraceptive use. There was no significant association between HPV positivity and the use of any type of contraceptive method.

No significant association was found between HPV positivity and education level, occupation, smoking (reported by only $6.4 \%$ of women), age at menarche, menopause or first birth, number of births, or history of spontaneous or voluntary abortion (reported by $73.6 \%$ of women). Only 44 women reported to have had at least one previous cytological smear (data not shown).

When we evaluated correlates of positivity for high-risk HPV types only, findings were similar to those found for any HPV type (data not shown).

\section{DISCUSSION}

Compared with similar studies in China using comparable methodology, our age-standardised HPV prevalence estimate in Shenyang $(17 \%)$ is slightly higher than that in the central rural province of Shanxi, known to be at high cervical cancer risk (14\%, Dai et al, 2006). The HPV prevalence in Shenyang is also similar to that found in high-risk areas for cervical cancer in Latin America (Molano et al, 2002; Matos et al, 2003; Ferreccio et al, 2004) and India (Franceschi et al, 2005), although lower than in sub-Saharan Africa (Thomas et al, 2004). In the absence of recent data on incidence or mortality of cervical cancer, such high HPV prevalence would suggest a large underlying burden of this disease in Shenyang and similar Chinese populations.

In contrast to previous studies in high-resource countries (Peto et al, 2004; Franceschi et al, 2006), no decline of HPV prevalence was seen with increasing age, the highest HPV prevalence being among middle-aged women. This age pattern is comparable to that seen in a similar survey in rural China (Dai et al, 2006), and is also compatible with the flat age-curves found in similar surveys in rural India (Franceschi et al, 2005) and sub-Saharan Africa (Thomas et al, 2004; Clifford and Franceschi, 2005). 
Table I Prevalence of HPV types by presence of cervical abnormalities and overall among 685 women. Shenyang, China, 2005

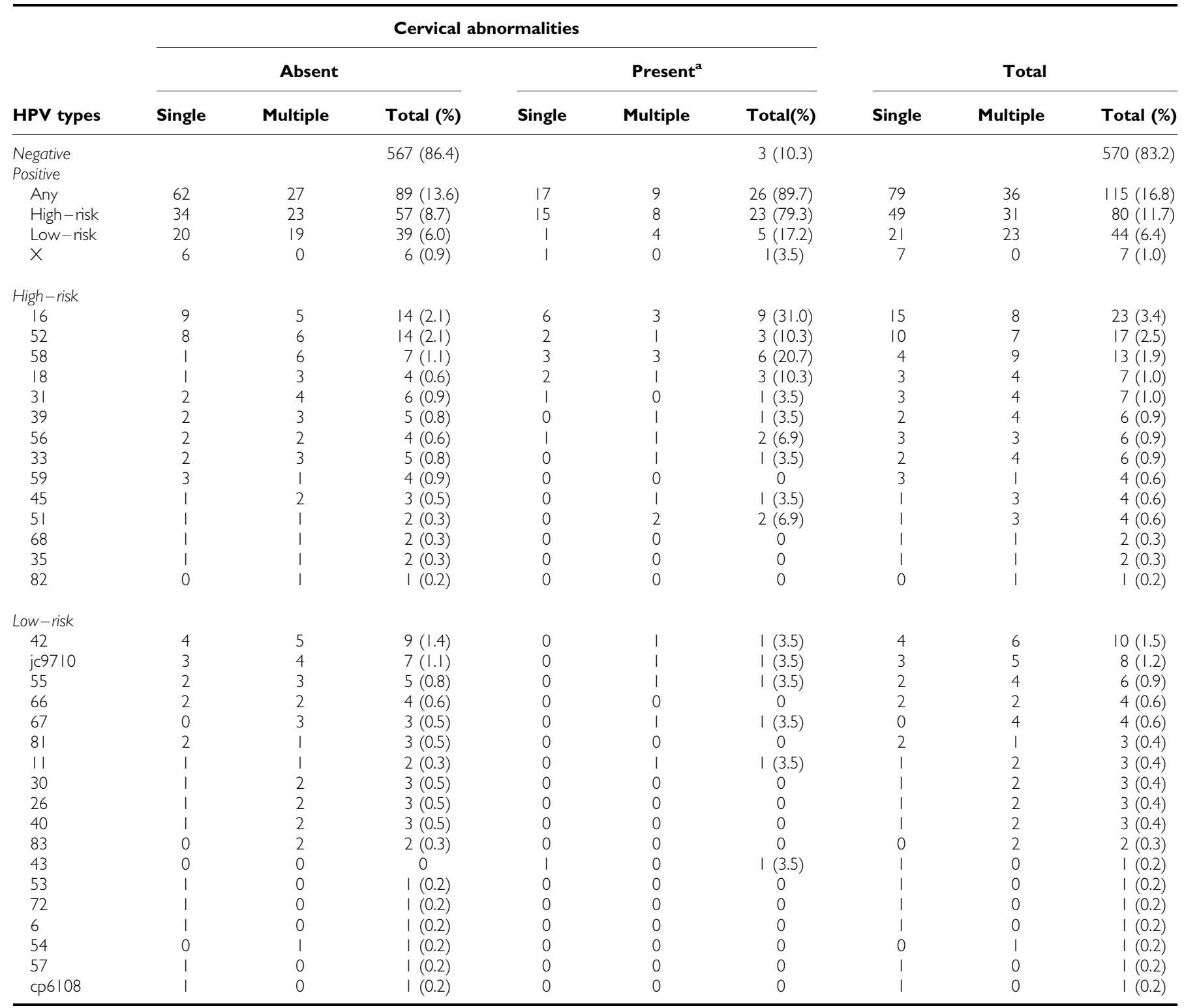

ancludes all histologically confirmed CINI and worse.

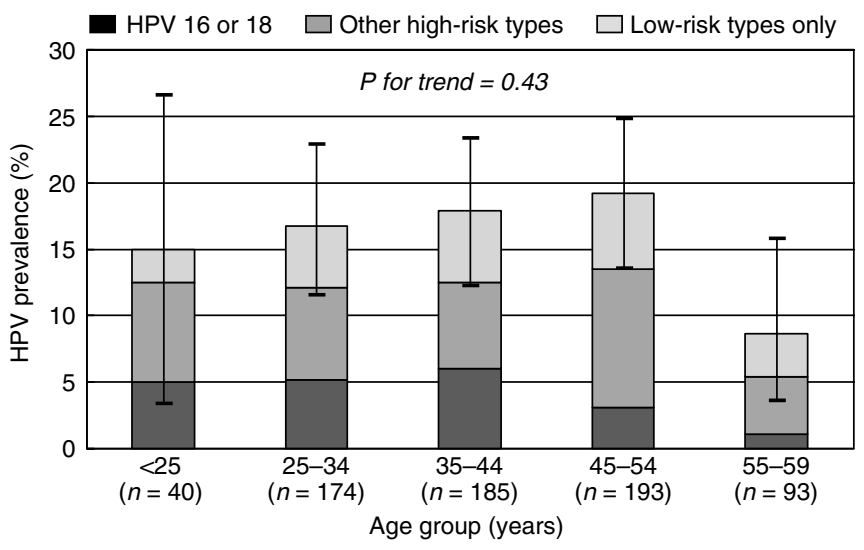

Figure I Age-specific prevalence of cervical HPV DNA and corresponding 95\% Cls. Shenyang, China, 2005.
As approximately $80 \%$ of HPV infections are estimated to be cleared in 12 months (Molano et al, 2003), the majority of the prevalent infections we detected are likely to be recent infections. Therefore, a flat age-curve suggests that in certain populations in developing countries, young women do not acquire new HPV infection more frequently than older women. As a majority of women in our study reported only one lifetime sexual partner, a large proportion of HPV infection at any age is likely to be related to the husband's extramarital sexual relationships.

The reporting of indicators of sexual behaviour, such as number of sexual partners and husband's extramarital sexual relationships were confirmed, as elsewhere (Vaccarella et al, 2006), to be the most important determinants of HPV prevalence in Shenyang.

As in most previous population-based surveys (Clifford et al, 2005), HPV16 was the most commonly identified type. Confirming findings from the preceding survey in rural China (Dai et al, 2006), HPV52 and 58 were more predominant than in non-Asian populations (Clifford et al, 2005). These three HPV types were 
Table 2 Detection of cervical HPV DNA according to marital status, indicators of sexual behaviour and use of contraceptive methods among 685 women. Shenyang, China, 2005

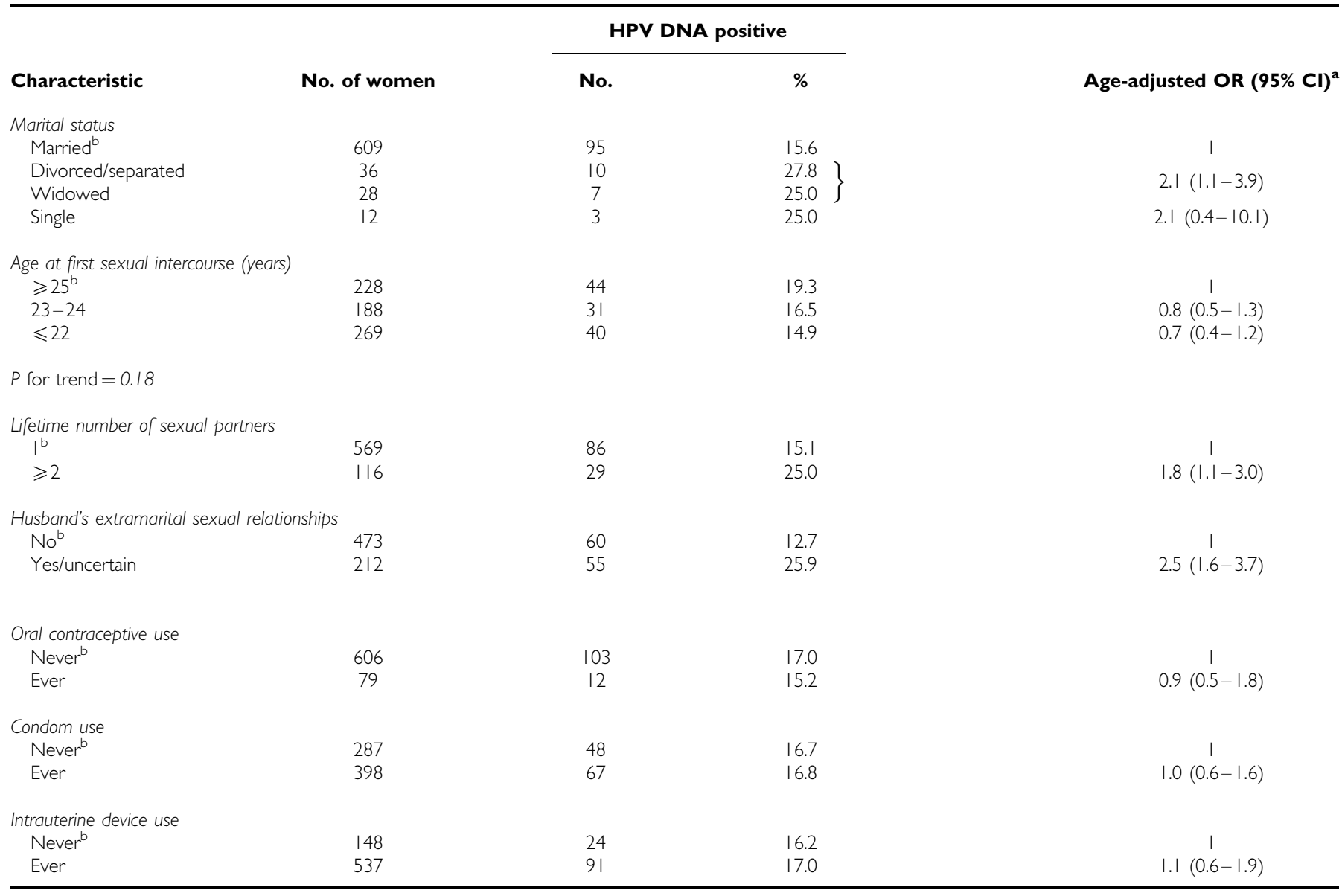

${ }^{a}$ Adjusted for age (5-year groups). ${ }^{b}$ Reference category.

also commonest among women with cervical abnormalities, supplementing the evidence that HPV52 and 58 are overrepresented in high-grade squamous intraepithelial lesions and cervical cancer from Eastern Asia compared to other world regions (Clifford et al, 2003).

Our present study has strengths and limitations. Among the former, the use of highly sensitive PCR assays and invitation of a representative sample of the general female population. The main limitation of the present study was the lack of complete participation of invited women. However, as HPV infection is asymptomatic, it is unlikely that participation was related to women's HPV infection status. Obtaining cervical cell specimens from unmarried women was confirmed to be difficult (Franceschi et al, 2006) and, therefore, the present HPV prevalence should be considered representative of married women only.

In conclusion, in the present absence of data on cervical cancer incidence and/or mortality, the disclosure of a high HPV

\section{REFERENCES}

Anh PT, Hieu NT, Herrero R, Vaccarella S, Smith JS, Thuy NT, Nga NH, Duc NB, Ashley R, Snijders POF, Meijer CJLM, Muñoz N, Parkin DM, Franceschi S (2003) Human papillomavirus infection among women in South and North Vietnam. Int J Cancer 104: 213-220

Chen XS, Gong XD, Liang GJ, Zhang GC (2000) Epidemiologic trends of sexually transmitted diseases in China. Sex Transm Dis 27: 138-142 prevalence would suggest an important underlying cervical cancer burden in Shenyang and similar Chinese populations. The historical picture of China being at relatively low-risk for cervical cancer may not apply to the whole country, and may be changing as a result of the marked behavioural changes accompanying rapid industrialisation and urbanisation. This has implications for the future cervical cancer burden and the priority to be given to preventing cervical cancer in China, especially, given the promising efficacy of prophylactic vaccines against HPV16 and 18.

\section{ACKNOWLEDGEMENTS}

Financial support was received from the Bill \& Melinda Gates Foundation (grant number 35537).
Clifford GM, Franceschi S (2005) HPV in sub-Saharan Africa [editorial]. Papillomavirus Rep 16: $322-326$

Clifford GM, Gallus S, Herrero R, Muñoz N, Snijders PJF, Vaccarella S, Anh PTH, Ferreccio C, Hieu NT, Matos E, Molano M, Rajkumar R, Ronco G, de Sanjosé S, Shin HR, Sukvirach S, Thomas JO, Tunsakul S, Meijer CJLM, Franceschi S (2005) Worldwide distribution of human papillo- 
mavirus types in cytologically normal women in the International Agency for Research on Cancer HPV prevalence surveys: a pooled analysis. Lancet 366: $991-998$

Clifford GM, Smith JS, Plummer M, Muñoz N, Franceschi S (2003) Human papillomavirus types in invasive cervical cancer worldwide: a metaanalysis. $\mathrm{Br} J$ Cancer 88: $63-73$

Dai M, Bao YP, Li N, Clifford GM, Vaccarella S, Snijders PJF, Huang RD, Sun LX, Meijer CJLM, Qiao YL, Franceschi S (2006) Human papillomavirus infection in Shanxi Province, People's Republic of China: a population-based study. Br J Cancer 95: 96-101

Doll R, Payne P, Waterhouse J (eds) (1966) Cancer Incidence in Five Continents: A Technical Report. Berlin: Springer-Verlag (for UICC)

Ferreccio C, Prado RB, Luzoro AV, Ampuero SL, Snijders PJF, Meijer CJLM, Vaccarella S, Jara AT, Puschel KI, Robles SC, Herrero R, Franceschi S, Ojeda JM (2004) Population-based prevalence and age distribution of human papillomavirus among women in Santiago, Chile. Cancer Epidemiol Biomarkers Prev 13: 2271 - 2276

Franceschi S, Rajkumar R, Snijders PJF, Arslan A, Mahé C, Plummer M, Sankaranarayanan R, Cherian J, Meijer CJLM, Weiderpass E (2005) Papillomavirus infection in rural women in southern India. Br J Cancer 92: $601-606$

Franceschi S, Herrero R, Clifford G, Snijders PJF, Arslan A, Anh PTH, Bosch FX, Ferreccio C, Hieu NT, Lazcano-Ponce E, Matos E, Molano M, Qiao YL, Rajkumar R, Ronco G, de Sanjosé S, Shin HR, Sukvirach S, Thomas JO, Meijer CJLM, Muñoz N (2006) Variations in the age-specific curves of human papillomavirus prevalence in women worldwide. Int J Cancer 21 September [Epub ahead of print]

Jacobs MV, Walboomers JM, Snijders PJF, Voorhorst FJ, Verheijen RH, Fransen-Daalmeijer N, Meijer CJLM (2000) Distribution of 37 mucosotropic HPV types in women with cytologically normal cervical smears: the age-related patterns for high-risk and low-risk types. Int J Cancer 87: $221-227$

Matos E, Loria D, Amestoy G, Herrera L, Prince MA, Moreno J, Krunfly C, van den Brule AJ, Meijer CJLM, Muñoz N, Herrero R, Proyecto Concordia Collaborative Group (2003) Prevalence of human papillomavirus infection among women in Concordia, Argentina: a populationbased study. Sex Transm Dis 30: 593 - 599

Molano M, Posso H, Weiderpass E, van den Brule AJ, Ronderos M, Franceschi S, Meijer CJLM, Arslan A, Muñoz N (2002) Prevalence and determinants of HPV infection among Colombian women with normal cytology. Br J Cancer 87: $324-333$

Molano M, van den Brule A, Plummer M, Weiderpass E, Posso H, Arslan A, Meijer CJLM, Muñoz N, Franceschi S, the HPV Study Group (2003) Determinants of clearance of human papillomavirus infections in Colombian women with normal cytology: a population-based, 5 year follow-up study. Am J Epidemiol 158: 486-494

Parkin DM, Whelan SL, Ferlay J, Thomas DB, Teppo L (2002) Cancer Incidence in Five Continents, Vol. VIII. IARC Scientific Publications No. 155. Lyon: IARC Press

Peto J, Gilham C, Deacon J, Taylor C, Evans C, Binns W, Haywood M, Elanko N, Coleman D, Yule R, Desai M (2004) Cervical HPV infection and neoplasia in a large population-based prospective study: the Manchester cohort. Br J Cancer 91: $942-953$

Sukvirach S, Smith JS, Tunsakul S, Muñoz N, Kesararat V, Opasatian O, Chichareon S, Kaenploy V, Ashley R, Meijer CJLM, Snijders PJF, Coursaget P, Franceschi S, Herrero R (2003) Population-based human papillomavirus prevalence in Lampang and Songkla, Thailand. J Infect Dis 187: 1246 - 1256

Thomas JO, Herrero R, Omigbodun AA, Ojemakinde K, Ajayi IO, Fawole A, Oladepo O, Smith JS, Arslan A, Muñoz N, Snijders PJF, Meijer CJLM, Franceschi S (2004) Prevalence of papillomavirus infection in women in Ibadan, Nigeria: a population-based study. Br J Cancer 90: 638-645

Vaccarella S, Franceschi S, Herrero R, Muñoz N, Snijders PJF, Clifford GM, Smith JS, Lazcano-Ponce E, Sukvirach S, Shin HR, de Sanjosé S, Molano M, Matos E, Ferreccio C, Anh PTH, Thomas JO, Meijer CJLM (2006) Sexual behavior, condom use and HPV: pooled analysis of the International Agency for Research on Cancer HPV Prevalence Surveys. Cancer Epidemiol Biomarkers Prev 15: $326-333$

van den Brule AJ, Pol R, Fransen-Daalmeijer N, Schouls LM, Meijer CJLM, Snijders PJF (2002) GP5+/6+ PCR followed by reverse line blot analysis enables rapid and high-throughput identification of human papillomavirus genotypes. J Clin Microbiol 40: 779-787

Yang L, Huangpu XM, Zhang SW, Lu FZ, Sun XD, Sun J, Mu R, Li LD, Qiao YL (2003a) Changes of mortality rate for cervical cancer during 1970's and 1990's periods in China. Acta Acad Med Sin 25: 386-390

Yang L, Parkin DM, Li L, Chen Y (2003b) Time trends in cancer mortality in China: 1987-1999. Int J Cancer 106: $771-783$ 